\title{
Synthesis and Characterization of HfC/SiC Ceramic Nanoparticles
}

\author{
L.G. Ceballos-Mendivil1 ${ }^{1}$, J.C. Tánori-Córdova ${ }^{2}$, J.A. Baldenebro-López ${ }^{1}$, R.A. Soto-Rojo ${ }^{1}$, F.J. \\ Baldenebro-López ${ }^{1}$ \\ 1. Facultad de Ingeniería Mochis, Universidad Autónoma de Sinaloa, Los Mochis, Sinaloa, México \\ 2. Depto. de Investigación en Polímeros y Materiales, Universidad de Sonora, Hermosillo, Sonora, \\ México
}

Hafnium carbide (HfC) has been investigated in the last ten years, due to its great potential in applications of ultra-high temperature, because has unique properties such as high melting point $\left(3900^{\circ} \mathrm{C}\right)$, high absorbance values, surficial area, good thermomechanical and thermochemical properties. Hence, it is a promising material for tools, rocket nozzles, aircraft, spaceships and transmitters [1, 2]. Feng et al. [3] synthesized $\mathrm{HfC} / \mathrm{SiC}$ nanocomposites via spark plasma sintering (R-SPS) of $\mathrm{HfC}$ and $\mathrm{HfSi}{ }_{2}$ nanomaterials, using high energy ball mill during $2 \mathrm{~h}$ in dry conditions, which were densified at $1750^{\circ} \mathrm{C}-1850^{\circ} \mathrm{C}$ by SPS during 10 minutes under vacuum axial pression of $40 \mathrm{MPa}$, obtaining a homogeneous microstructure.

The reagents used to synthesize the HfC precursor, were: hafnium tetrachloride (HfCl4, 98\%), pectin $\left(\mathrm{C}_{6} \mathrm{H}_{10} \mathrm{O}_{7}, 74 \%\right)$ and distilled water as solvent. The reagents used to synthesize the SiC precursor, were: calcined SBA-15, sucrose $\left(\mathrm{C}_{12} \mathrm{H}_{22} \mathrm{O}_{11}, 99.5 \%\right)$, distilled water as solvent and sulfuric acid $\left(\mathrm{H}_{2} \mathrm{SO}_{4}\right)$ as catalyst. The synthesis of $\mathrm{HfC} / \mathrm{SiC}$ composite was realized in 3 steps: i) $\mathrm{HfCl}_{4}$ and pectin were mixed through constant agitation at $40^{\circ} \mathrm{C}$ for $3 \mathrm{~h}$ using sol-gel process. Next a drying is realized at $110^{\circ} \mathrm{C}$ for $24 \mathrm{~h}$ obtaining the $\mathrm{HfC}$ precursor powder; ii) SBA-15, sucrose and $\mathrm{H}_{2} \mathrm{SO}_{4}$ were mixed and dried at $100^{\circ} \mathrm{C}$ for $6 \mathrm{~h}$, next the temperature is raised at $160^{\circ} \mathrm{C}$ under Argon atmosphere for $3 \mathrm{~h}$, obtaining the $\mathrm{SiC}$ precursor powder; iii) The HfC and SiC precursor powders, obtained to low temperature, were milled and mixed in a agate mortar $(70 \%$ wt $\mathrm{HfC}$ and $30 \%$ wt $\mathrm{SiC})$, next a heat treatment was carried out at $1600^{\circ} \mathrm{C}$ under Argon atmosphere for $3 \mathrm{~h}$, obtaining the $\mathrm{HfC} / \mathrm{SiC}$ composite.

The phases composition of the samples was investigated by XRD, with the results shown in Figure 1. Characteristic peaks of crystalline $\mathrm{HfC}$, at $2 \theta=33.5^{\circ}(111), 38.8^{\circ}(200), 56.1^{\circ}(220), 66.8^{\circ}(311)$ and $70.2^{\circ}$ (222) and the peaks corresponding to $\beta$-SiC, at $2 \theta=35.5^{\circ}(111), 59.9^{\circ}(220)$, and $71.7^{\circ}(311)$ were observed for the sample synthesized. It should be noted that characteristic peaks of $\mathrm{m}-\mathrm{HfO}_{2}\left(2 \theta=28.3^{\circ}(-111)\right.$, and $30.4^{\circ}(111)$ ), which are dominant phases, were detected at very low intensity for this ceramic sample. This can be attributed to the non-oxygen containing system.

The morphology of HfC-SiC ceramics is shown in Figure 2. It can be seen that the particle size was to nanoscale and microscale. The EDS analysis (Figure 3) reveals that the main elements composing the powders are $\mathrm{Hf}, \mathrm{Si}, \mathrm{C}$ and $\mathrm{O}$, indicating the presence of $\mathrm{HfC}$ and some oxygen forming oxycarbide compounds with $\mathrm{Hf}(\mathrm{C}, \mathrm{O})$ formulae according to the XRD results shown in Figure 1.

Novel sources for the obtaining of $\mathrm{HfC}-\mathrm{SiC}$ ceramic particles were synthesized using: hafnium tetrachloride, pectin and distilled water as solvent, as well as, calcined SBA-15, sucrose, distilled water as solvent and sulfuric acid as catalyst. The reaction of the precursors at $1600^{\circ} \mathrm{C}$ resulted in the formation of crystalline phases of $\mathrm{HfC}, \mathrm{SiC}$ and $\mathrm{HfO}_{2}$. The products obtained were mainly nanoparticles, with few microparticles. 


\section{References:}

[1] B. Matović et al, Key Eng. Mater. 616 (2014), p. 1.

[2] H.J. Lee et al, Sol. Energy 86 (2012), p. 1576.

[3] L. Feng, S.H. Lee and J. Yin, J. Am. Ceram. Soc. 99 (2016), p. 2632.
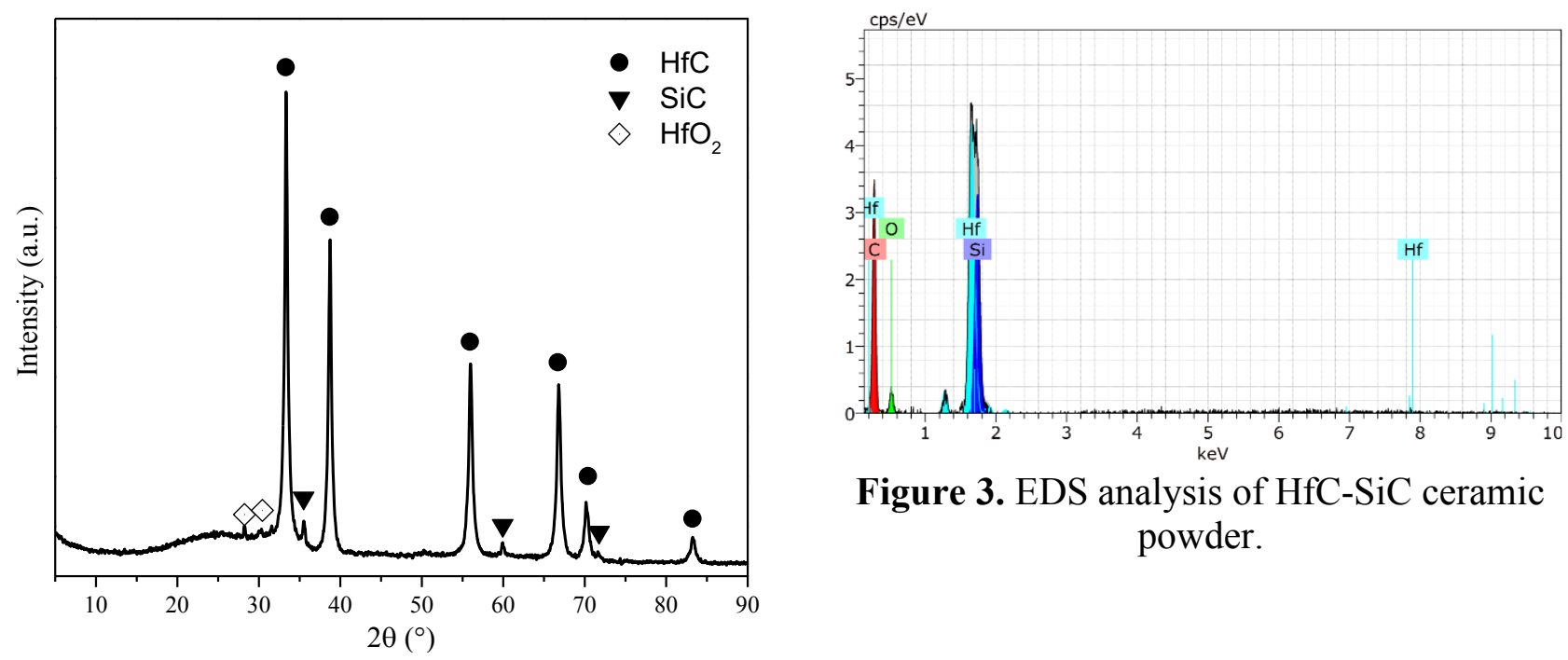

Figure 3. EDS analysis of $\mathrm{HfC}-\mathrm{SiC}$ ceramic powder.

Figure 1. XRD patterns of HfC-SiC ceramic powder.

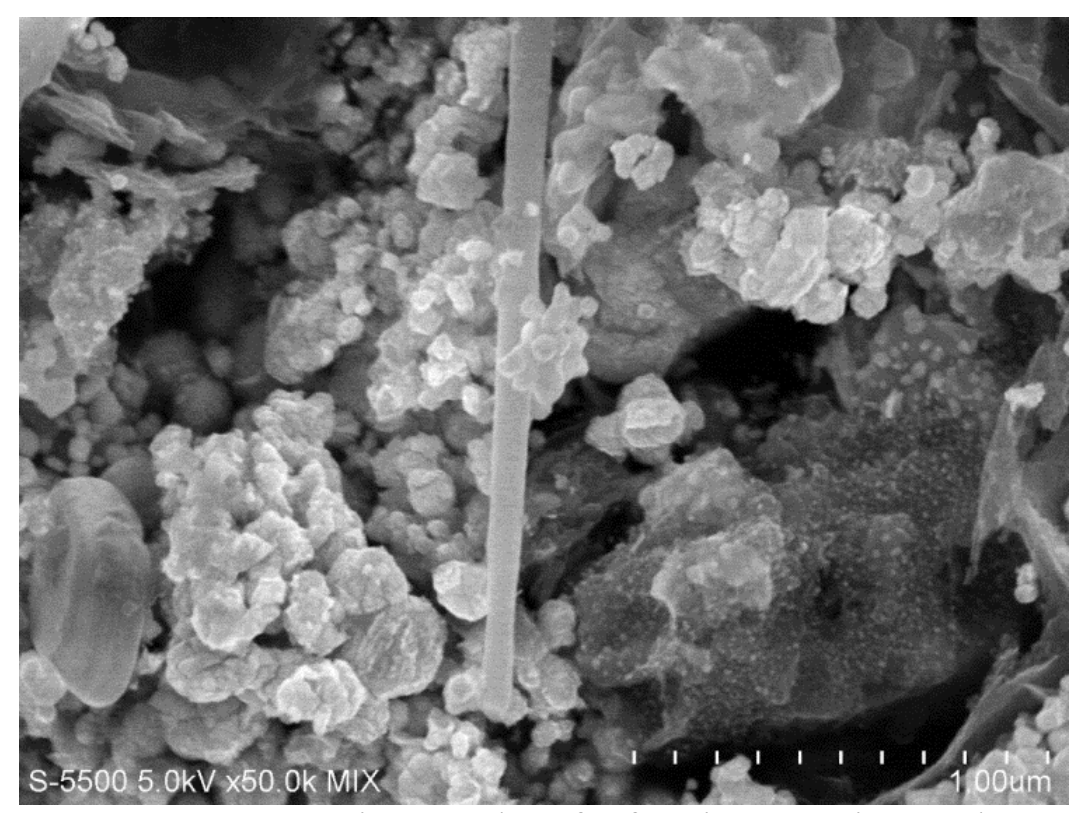

Figure 2. SEM micrography of HfC-SiC ceramic powder. 